\title{
La ciencia es ciencia de la ideología en Louis Althusser
}

\author{
María Cecilia Padilla* \\ FACUNDO NORBERTO BEY**
}

Artículo recibido: 3 de marzo de 2015

Artículo aprobado: 30 de julio de 2015

Doi: dx.doi.org/10.12804/desafios28.1.2016.09

Para citar este artículo: Padilla, M. C., \& Bey, F. N. (2016). La ciencia es ciencia de la ideología en Louis Althusser. Desafios, 28(I), 371-398. Doi: dx.doi.org/10.12804/desafios28.1.2016.09

\section{Resumen}

A 25 años de su muerte, los escritos de Louis Althusser continúan siendo tan polémicos y controvertidos como lo fueron en el momento de su publicación. La siguiente investigación se propone analizar uno de los temas que más controversias y críticas suscitó en la década de los sesenta, momento por demás polémico dentro de su producción intelectual: la relación entre la ciencia e ideología. ¿Se trata de una llana oposición?, ¿son la ciencia y la ideología dos estructuras claramente diferenciadas?, ¿es acaso la ciencia la salida de la ideología?, ¿es la ciencia la verdad y la ideología el error? A través de un estudio pormenorizado de los textos publicados en la década

\footnotetext{
* Licenciada en Ciencia Política de la Universidad de Buenos Aires (UBA). Maestranda de la Universidad Nacional de General San Martín (UNSAM), Instituto de Altos Estudios Sociales (IDAES). Traductora literaria y de especialidad en idioma Inglés, UMSA, e Intérprete en idioma Inglés, UMSA. Ayudante Ad Honorem de la materia "Filosofía y Métodos de las Ciencias Sociales", Carrera de Ciencia Política, Facultad de Ciencias Sociales, Universidad de Buenos Aires. Ciudad Autónoma de Buenos Aires, Argentina. Correo electrónico: padilla. mcecilia@gmail.com

** Licenciado en Ciencia Política de la Universidad de Buenos Aires (UBA). Maestrando de la Universidad Nacional de General San Martín (UNSAM), Instituto de Altos Estudios Sociales (IDAES). Ayudante de Segunda Ad bonorem en la materia "Fundamentos de Ciencia Política", Carrera de Ciencia Política, Facultad de Ciencias Sociales, Universidad de Buenos Aires. Ciudad Autónoma de Buenos Aires, Argentina. Correo electrónico: facundo.bey@ gmail.com
} 
señalada, este trabajo buscará dar cuenta del pensamiento de Althusser en relación con esta temática en el marco de sus valiosos aportes al pensamiento marxista.

Palabras clave: Ciencia, ideología, materialismo histórico.

\title{
Science is Science of Ideology in Louis Althusser
}

\begin{abstract}
25 years after his death, Louis Althusser's writings continue to stir up controversy. This article analyzes an issue that aroused criticism during the 1960s, an extremely polemical moment within his intellectual production: the relation between science and ideology. Is it plain opposition? Are science and ideology two clearly differentiated structures? Does science mean the end of ideology? Does science represent the truth and ideology a mere error? The article thoroughly studies Althusser's publications during the period of the 1960s in order to shed light on his thinking regarding this topic.
\end{abstract}

Keywords: Science, ideology, historical materialism.

\section{A ciência é ciência da ideologia em Louis Althusser}

\begin{abstract}
Resumo
A 25 anos de sua morte, os escritos de Louis Althusser continuam sendo tanto polémicos e controvertidos quanto o foram no momento de sua publicação. A seguinte pesquisa propõe-se analisar um dos temas que mais controvérsias e críticas suscitou na década dos sessenta, momento por demais polémico dentro de sua produção intelectual: a relação entre a ciência e ideologia: trata-se de uma simples oposição? São a ciência e a ideologia dois estruturas claramente diferenciadas? É acaso a ciência a saída da ideologia? É a ciência a verdade e a ideologia o erro? Através de um estudo pormenorizado dos textos publicados na década assinalada, este trabalho buscará dar conta do pensamento de Althusser em relação com esta temática no marco de seus valiosos aportes ao pensamento marxista.
\end{abstract}

Palavras -chave: Ciência, ideologia, materialismo bistórico. 


\section{Introducción}

En ensayos y trabajos actuales sobre Louis Althusser son recurrentes las alusiones al "olvido y adulteración de sus categorías" (Romé, 2011, p. 10), al silenciamiento de sus reflexiones, a la lectura esquemática y fragmentaria de sus intervenciones (Sosa, 2011) a la desaparición de su nombre de las bibliografías y programas universitarios. Althusser escribió en Para leer El capital "durante casi un siglo, la filosofía universitaria ha cubierto a Marx con la tierra del silencio, que es la tierra de los cadáveres" (2010, p. 37); este diagnóstico parece aplicarse también a él en estos últimos cuarenta años. Un cadáver, un muerto, o acaso una "figura espectral", la de aquel "que ha abandonado la vida o fue abandonado por ella" (Catanzaro, 2011, p. 66). Sin embargo, tal vez ese silencio no sea el de un muerto sino, en palabras de Balibar, "el de un hombre enterrado en vida, de un muerto viviente en la filosofía y en la política" (2005, p. 2); y en consecuencia, entonces, tal vez el sentido de la figura espectral también sea otro: el de lo extraño, el de aquello que queremos acallar y marginar porque nos inquieta.

Este trabajo pretende aproximarse a una cuestión que generó inquietud entre sus contemporáneos, pero que después fue silenciada, y que precisamente por eso continúa siendo inquietante: el vínculo entre la ciencia y la ideología. ¿Se trata de una llana oposición? Si lo es, ¿cuál es su contenido?, ¿es la diferencia Iluminista entre la verdad y el error, de un error que hay que corregir?, ¿se trata de dos estructuras absolutamente distintas? Como veremos a continuación, esta problemática se enmarca en un debate dentro de las filas del marxismo y del comunismo francés, entre Althusser -en su doble condición de filósofo y miembro del Partido Comunista- y otros intelectuales y miembros del partido en torno a la conceptualización científica del marxismo. Althusser se abocó a la tarea de librar al marxismo de su dogmatismo y reconstruir teóricamente a la teoría marxista, al considerar este el único camino para apuntalar la acción revolucionaria del partido.

Creemos que una forma oportuna de abordar la relación entre la ciencia y la ideología es a partir de aquella frase que Pierre Macherey escribió en la Nowvelle Critique en 1965, que Althusser cita unos meses 
más tarde en su maravilloso prefacio a Para Leer el Capital: "La ciencia es ciencia de la ideología”. Precisamente ésta será la frase que guiará nuestra lectura de la producción de Althusser de la década de los sesenta, la cual entendemos que tiene más de un significado, todos ellos compatibles con las investigaciones althusserianas sobre los avatares de la relación entre la ciencia y la ideología.

\section{Volver a Marx: el corte epistemológico y la ideología como prehistoria de la ciencia}

Partimos de la conjetura de que el vínculo entre la ciencia y la ideología se halla presente en Althusser desde sus primeros escritos bajo una vestidura muy particular: la definición del carácter científico, de la cientificidad de una teoría, en particular de la teoría de Marx. (Althusser, 2011, p. 47). Su intervención busca trazar una "línea de demarcación" entre la teoría marxista científica y aquellas "tendencias ideológicas" ajenas al marxismo. Como Althusser confiesa en el prefacio a La revolución teórica de Marx (2011), el problema que domina sus trabajos de los años sesenta es "la definición de la especificidad irreductible de la teoría marxista" (2011, p. X), es decir, el esclarecimiento y exploración del gigantesco descubrimiento de Marx, de aquel nuevo continente científico que él abrió al conocimiento humano: el Continente de la Historia, el materialismo histórico.

Por supuesto, esta preocupación no se da en el vacío, sino que nace en una coyuntura específica y en el contexto de una polémica particular: el reconocimiento de "una parálisis en la vitalidad crítica del marxismo" (De Gainza, 2011, p. 84) cuya causa encuentra Althusser en la precariedad de la teoría. Concretamente, Althusser advierte que el humanismo teórico, revitalizado en su rechazo al "culto a la personalidad" del período stalinista, redunda paradójicamente en un nuevo dogmatismo, una mera "reacción ideológica", cuyas consecuencias políticas no son advertidas por los intelectuales comunistas de la URSS y de los partidos comunistas de Occidente. Es en este contexto donde para Althusser se torna urgente la crítica epistemológica de la obra de Marx por medio de la demarcación científica, que permite 
distinguir al llamado "joven Marx" del "Marx Maduro", este último depurado de sus elementos humanistas.

La pregunta nos urge: ¿Por qué caracteriza Althusser al humanismo como una "reacción ideológica"? Responder nos obliga a "volver a Marx'. Así como Lacan vuelve a Freud para rescatarlo del revisionismo que permitió la caída del psicoanálisis en una multiplicidad de "ismos" (Althusser, 1988, pp. 60-71), Althusser vuelve a Marx para "defender la teoría marxista contra las tendencias del revisionismo que lo amenazan" (1967, p. 7). "No fue fácil para el marxismo resistir la irrupción ideológica "humanista" contemporánea y los distintos asaltos de la ideología burguesa" dijo en la entrevista otorgada a Maria-Antonieta Macciocchi en 1968 (2012, p. 5). Por eso, su consigna es leer. Leer a Marx para armarse teóricamente y así resistir las embestidas de aquellos que opacan su descubrimiento. Leer a Marx porque en sus palabras está contenida la respuesta. Leer a Marx de forma crítica, al pie de la letra, sin fondo.

Este retorno nos conduce de lleno a una categoría central en los primeros trabajos del filósofo, categoría que toma prestada de Gastón Bachelard y en la que, en palabras de Balibar, "se concentraron las controversias, los ataques y las defensas" (Balibar, 2004, p. 9): la noción de corte epistemológico. Nos abocaremos a ella para pensar el primer vínculo entre la ciencia y la ideología. Comenzar por la ruptura no es azaroso, y tampoco lo ha sido en Althusser. Entendemos que es a partir de la noción de ruptura que nuestro autor puede "pensar la mutación de la problemática teórica contemporánea a la fundación de una teoría científica" (Althusser, 2011a, p. 23). En sus palabras, la "ruptura" le permite pensar la relación entre la ciencia y la ideología como la relación de una ciencia con su pasado, con su prehistoria. Sin embargo, no debemos dejarnos llevar por la tendencia iluminista e historicista que permite pensar este vínculo como un continuo ascendente de sentido sagital que va del engaño o el error hacia la verdad o la ciencia. Así, como asevera Althusser en el prefacio a Para leer el capital "Debemos modificar totalmente la idea que nos hacemos del conocimiento, abandonar el mito especular de la visión, de la lectura inmediata, y concebir al conocimiento como producción” (2012, 
p. 29). Pero, ¿cuál es esa idea que "nos hacemos" del conocimiento? Para Althusser la concepción que ha dominado durante siglos a la filosofía occidental es la que él llama "concepción empirista del conocimiento", que se ha presentado bajo diferentes formas, ya sea el empirismo trascendente de Descartes o el sujeto trascendental de Kant, e incluso el idealismo objetivo de Hegel.

Esta concepción empirista del conocimiento es caracterizada por el autor como una "transcripción profana" de la concepción "religiosa" de la lectura -de esa lectura inmediata que cree que es posible leer la esencia en la transparencia de la existencia, lectura inocente que entiende que el concepto se hace visible a cielo descubierto- "con la sencilla diferencia de que la transparencia no está dada en ella de golpe, sino que está separada" (Althusser, 2012, p. 43) por un velo que nos sustrae la esencia. Para ella, el proceso de conocimiento es una relación entre un sujeto y un objeto ya dados, una relación en la que la operación de conocimiento toma la forma de una abstracción puesta en marcha por la motivación del sujeto de aprehender la objetividad a la que se enfrenta, de abstraer del objeto real, compuesto por la esencia y la inesencia, por lo puro y lo impuro, precisamente la esencia real oculta detrás de lo inesencial. Al creer que el conocimiento ya está allí, inscripto en lo concreto y captable de manera inmediata, que puede ser "simplemente recogido de la realidad", el proceso se revela como una "operación de limpieza”, en la que el sujeto separa el núcleo profundo, depurándolo de su aspecto exterior y superficial para ponerse en posesión de ese objeto real (De Gainza, 2011, p. 254).

Si bien este proceso de abstracción evidencia la existencia de dos objetos, un objeto real y un objeto de conocimiento, la tradición empirista niega que ella misma trate a ambos de un modo indiferenciado y, en cambio, afirma únicamente la existencia del objeto real. Este error ya lo había anunciado Baruch Spinoza, desoído por sus contemporáneos y sus predecesores, al afirmar que "no hay que confundir dos objetos, la idea del círculo, que es el objeto de conocimiento, con el círculo, que es el objeto real" (Althusser, 2012, pp. 46-47). Marx, siguiendo el camino abierto por Spinoza, rechaza la indistinción entre ambos objetos, y aún más, destaca que el proceso real y el proceso 
de conocimiento son distintos y ocurren en "lugares" diferentes: uno en el mundo, otro en el pensamiento, respectivamente. El proceso de conocimiento es una apropiación de lo concreto a partir de la producción de un concepto para ese objeto de conocimiento. El conocimiento, entonces, ya no se revela como una extracción, sino como un proceso que ocurre por entero en el pensamiento, que "se apropia de lo concreto y lo reproduce" (Althusser, 2010, p. 46).

Es preciso dejar en claro que el pensamiento de Marx no recae en el mismo idealismo de la conciencia que él mismo critica, pues el pensamiento del que aquí se trata no es ni "la facultad de un sujeto trascendental" ni "de una conciencia absoluta a quien el mundo haría frente como materia", ni tampoco "la facultad de un individuo psicológico" (Althusser, 2012, p. 50). Por el contrario, se trata un sistema específico definido por sus condiciones y su práctica, por una estructura propia, que no es más que un tipo de combinación específica entre una materia prima, sus medios de producción y la relación con otras estructuras de la sociedad. "Conocer es producir el concepto adecuado del objeto por la puesta en acción de los medios de producción teóricos (teoría y método) aplicados a una materia prima" (Althusser, 2012, p. 38). Esa materia prima -materia siempre ya elaborada, siempre ya transformada- consiste siempre-ya en una articulación compleja, una "Verbindung" propia, que combina elementos sensibles, técnicos e ideológicos a la vez.

Entender el conocimiento como producción nos aleja de todo tipo de lectura inocente, inmediata. Justamente, la disruptiva lectura althusseriana implica una disposición intelectual que busca descubrir lo no descubierto en la aparente continuidad del texto mismo, que no hace preguntas falsas que ya sabe que encontrará en la literalidad, sino que interroga las preguntas a las que habría que dar respuestas; una lectura que hace ver lo que el texto dice sin decirlo y no dice al decirlo, "porque es el texto clásico mismo el que nos dice qué calla, su silencio son sus propias palabras"(Althusser, 2012, p. 40), o de otro modo, las respuestas a las que le faltan preguntas. "Se trata de producir, pues, en el sentido estricto de la palabra, lo que parece significar: hacer manifiesto lo que está latente; pero esto quiere decir 
transformar (para dar a una materia prima preexistente la forma de un objeto adaptado a un fin) aquello que en cierto sentido existe-ya" (Althusser, 2012, p. 40). La lectura althusseriana entiende el proceso de producción de conocimientos como el resultado de una práctica teórica, que parte necesariamente de abstracciones y generalizaciones.

¿Cuáles son esas generalidades de las que parte? En La revolución teórica de Marx (2011a), Althusser explica que la constitución de una ciencia es un trabajo de producción, de transformación y elaboración de una materia prima, que denomina Generalidad I en una Generalidad III. La primera es abstracta, constituida por "hechos ideológicos" de una práctica ideológica anterior; la segunda es concreta, compuesta por hechos científicos, es decir, que es conocimiento. La Generalidad II es precisamente "la que trabaja" (2011a, p. 152) sobre la Generalidad I, la teoría donde se plantean los problemas de esa ciencia en formación. A través de la crítica que efectúa la Generalidad II se elaboran los hechos científicos, y se llega a la Generalidad III, el concreto-depensamiento que nos da el conocimiento de su objeto, el concreto-real. Entre ambas generalidades no hay continuidad sino producción, una producción que implica una mutación, una ruptura. Se trata de identificar el campo propio, abandonar la problemática ideológica anterior y fundar "en otro elemento", en el campo de una nueva problemática (esta vez científica) la actividad de una nueva teoría. Una problemática es el terreno y el horizonte de una estructura teórica definida, que constituye su condición de posibilidad, y "determina las formas de planteamiento del problema” (Althusser, 2012, p. 30): es el sistema orgánico de conceptos fundamentales. Es decir, la problemática determina lo visible como visible, y lo invisible como invisible. El proceso de producción de conocimiento de una ciencia se da dentro de una problemática mediante la transformación incesante de su objeto, profundizando en el conocimiento de ese objeto (Althusser, 2012, p. 169). Así, se van haciendo visibles nuevos aspectos que antes no lo eran, tal como sucede con las regiones geográficas, propone nuestro autor adelantando una metáfora que ya ampliaremos.

Esto que acabamos de describir es lo que el autor entiende como proceso de desarrollo de una ciencia ya constituida, en la que el cono- 
cimiento se desarrolla sin modificar ni "los contornos de la región" ni la "problemática". Sin embargo, aquí nos interesan los "momentos críticos", de cortes y rupturas, que ocurren cuando se produce un nuevo problema, cuando surgen respuestas sin preguntas, que es necesario formular pero no es posible hacerlo con los elementos ni las relaciones que plantea esa problemática. Aquí ocurre ese "cambio de terreno" que mencionamos, que implica la transformación de la estructura del objeto de conocimiento por completo, y con ella, la mutación de la problemática teórica. Podemos, con todo derecho, hablar así de un objeto nuevo, de conceptos nuevos, de una nueva terminología, pues se trata, con todas las letras, de una revolución teórica. Eso es lo que ha ocurrido en las matemáticas con Tales, en la física con Galileo, y en la historia reciente, con Freud, cuyo objeto teórico, el inconsciente, nada tiene que ver con las numerosas corrientes de la psicología moderna. Justamente eso es también lo que sucede con Marx.

Vemos entonces que el nacimiento de una ciencia no se da "dando vuelta la ideología", sino que es fruto de "un inmenso trabajo teórico específico, una práctica teórica irreemplazable, extremadamente ardua y difícil" (Althusser, 2008, p. 167). Toda ciencia "sale de su prehistoria", necesariamente ideológica, tras una "ruptura epistemológica" que la arranca y separa de ella. Esta ruptura no es "espontánea", no ocurre en la sociedad, ni en la economía, y mucho menos en la mente de un pensador o de un científico, sino que es el resultado de una producción: "este corte [es correlativo] a un proceso real, al de constitución de la ciencia, que nace de la ideología misma, por un trabajo teórico", por un rudo trabajo de crítica "que culmina en un punto crítico explotando en una ruptura que instaura el nuevo campo donde va a establecerse la ciencia" (Althusser, 1967, p. 32).

Entendemos ahora por qué los senderos que Althusser abre nos llevan, en sus palabras, a "una revolución en la concepción tradicional de la historia de las ciencias” que aún se encuentran impregnadas de la ideología de la filosofía de las luces, de un racionalismo teleológico e idealista, que entiende a la historia de la razón como una historia lineal y de desarrollo continuo; como el relato de la toma de conciencia 
progresiva de una Razón a través de la superación de estadios inferiores de conciencia, de un trabajo de la negación del Espíritu sobre las propias negaciones que él produjo para llegar al saber absoluto, al saber de sí mismo. Para Althusser es necesario abandonar esta concepción hegeliana de la lógica expresiva, que no es más que un "compendio de ideología" y comenzar a pensar la historia del desarrollo del conocimiento como una historia jalonada de discontinuidades y rupturas.

Aquí damos con una primera relación entre el binomio que interroga nuestro artículo: la ciencia y la ideología. Sin embargo, como vimos, se trata de una ciencia nueva, que se está constituyendo, y lo hace separándose, también de manera novedosa, de "las ideologías teóricas pre-científicas que ocupaban el terreno sobre el cual ella se establece" (Althusser, 2010, p. 51). Pero, ¿de qué se trata esta particular oposición entre ciencia e ideología? En principio, encierra una aparente paradoja: dado que la existencia de la ciencia instaura en la historia de las teorías este corte, esta oposición ciencia/ideología está fundada sobre una retrospección o recurrencia. Es decir, la ciencia nace de la ideología, y sin embargo esta ideología sólo recibe este calificativo "a condición de la ciencia de ella nacida y separada de ella" (Althusser, 1967, p. 33).

Esta relación entre la ciencia y la ideología determina el principio que hace ser tal a la primera. Una ciencia comienza, pero no se detiene nunca. Comienza con Marx pero no puede detenerse ante él. Este carácter dinámico está dado por su posición respectiva de la ideología. La ciencia es esencialmente crítica de la ideología y la ideología -las ideologías- es la posibilidad de la ciencia:

Pues la ciencia, que nace en y de la ideología a la cual ella se arranca no es, una vez nacida, asegurada y establecida en su dominio como en un mundo cerrado y puro que no tenga que vérselas más consigo misma. No cesa, viva, de trabajar sobre una materia prima afectada de (por la) ideología (Althusser, 1967, p. 33).

Por eso "el trabajo de crítica y transformación de lo ideológico en científico, que inaugura toda ciencia no cesa jamás de ser el trabajo de 
una ciencia establecida" (Althusser, 1967, p. 33). Consecuentemente, si fuera una superación de la ideología, si su tarea fuera disipar la ideología, criticarla como error, incluso erradicarla, la ciencia en cuanto tal dejaría de existir. En el prefacio ya citado, tras referirse a la ruptura epistemológica, Althusser dice: "que nos veamos en la necesidad de plantearlo también en relación a Marx (las cursivas son de Althusser) es algo que multiplica nuestras tareas" (2012, p. 52). Y ciertamente lo hace, pues nos lleva a pensar en otro vínculo entre la ciencia y la ideología en el pensamiento althusseriano.

\section{La crítica de la ideología como crítica a sus pretensiones teóricas}

"La cuestión", como denomina Althusser al corte epistemológico, atraviesa la mayoría de los trabajos de este período, al menos desde 1963: "la cuestión de la historia de la evolución del pensamiento teórico de Marx, la cuestión del "corte epistemológico" entre la prehistoria ideológica y la historia científica, la cuestión de la diferencia teórica radical que separa para siempre las obras de juventud de El Capital (Althusser, 1967, p. 5). En efecto, como postulan numerosos pensadores marxistas, existen en el pensamiento de "dos Marx": uno joven y uno maduro. Sin embargo, no por esto podemos decir "la juventud de Marx pertenece al marxismo.” (Althusser, 2010, p. 68). En otras palabras, ¡Marx no siempre ha sido marxista! De hecho, en la evolución del pensamiento teórico de Marx ocurre una ruptura, un corte, que según Althusser, lo divide en dos grandes períodos, uno ideológico y uno científico: no-marxista y marxista, respectivamente. ¿Qué implica esta ruptura en el pensamiento marxiano?

Para Althusser, los escritos de juventud de Marx se encuentran imbuidos en el humanismo; allí, la esencia del hombre funda una teoría de la historia y una práctica política, fuera esta esencia la libertad-razón o la comunidad. Esta etapa, según Althusser, se divide en dos momentos. El primero es el momento racionalista liberal del jovencísimo Marx que defiende la libertad del hombre y le exige al Estado que realice su esencia y sea razón. El segundo momento refleja la desilusión ante un Estado que "permaneció sordo a la razón”, el concomitante 
encuentro con el humanismo teórico de Feuerbach (de los años 193945), quien lo "salva" del impase teórico al que los había echado la historia, lanzándoles un salvavidas teórico, la razón de esa sin-razón existente: la teoría de la alienación del Hombre.

Tenemos aquí un Marx para el que el hombre es el mundo del hombre (Althusser, 1967, p. 17). Sin embargo, a partir de la escritura de $L a$ ideología alemana, de aquella obra que no será publicada hasta después de su muerte, Marx rompe con toda teoría que funda la historia y la política en la esencia humana. El hombre deja de ser una categoría racional fundamental de la inteligencia de la Historia y se vuelve "irracional, irrisoria, vacía (...) la diversión de una ideología" (Althusser, 1967, p. 27). Marx no sólo rechaza al humanismo como fundamento teórico, sino que, incluso, lo define como una ideología. Esta ruptura, dice Althusser, se desprende de dos postulados básicos que eran la base de la concepción que durante siglos había sido considerada la "evidencia misma", y por ende incuestionable: la concepción reversiblemente empirista e idealista del mundo. Empirismo e idealismo se encuentran implicados, pues para que la esencia del hombre sea un atributo universal deben existir sujetos concretos, y para que estos sujetos sean hombres deben llevar en sí la esencia humana. Así, todo empirismo del sujeto implica un idealismo de la esencia y viceversa. $\mathrm{Al}$ rechazarlo, Marx se para sobre el terreno nuevo del materialismo.

Este rechazo, lejos de ser destructivo, es "productivo", "positivo", por ser en un mismo y único movimiento una ruptura que es un descubrimiento, un descubrimiento que es una fundación, y una fundación que es doble: la del materialismo histórico (la ciencia de la historia), y con ella -dado que todo descubrimiento científico implica una nueva filosofía - la del materialismo dialéctico (la filosofía marxista). Marx funda, entonces, una nueva problemática, una nueva manera de plantear los problemas al mundo, un nuevo método, nuevas formas para pensar un objeto, la actividad de una nueva teoría.

Recapitulemos: en el "pasaje" de la juventud a la madurez de Marx no existe una continuidad. No se trata de encontrar en el joven Marx "el germen" del Marx maduro, ni en el Marx maduro los comienzos 
de una teoría marxista. Althusser tampoco piensa la evolución y la transformación del pensamiento de Marx en términos de una "biografía intelectual", que supondría la posibilidad de leer la trayectoria del filósofo alemán a través de los procesos singulares que hilvanan sus ideas, de un desarrollo y progreso en el hilo de su pensamiento que va perfeccionando con el agregado de sucesivos elementos teóricos a lo largo del tiempo, de un origen hegeliano idealista que se mantiene siempre de fondo, pero que en parte critica tomando el materialismo sensualista de Feuerbach, articulación a la que suma la economía política clásica y las perspectivas utópicas del socialismo francés. Muy por el contrario, para pensar la "verdadera génesis dramática del pensamiento marxista" es necesario rechazar la lógica de la acumulación y la articulación, "renunciar al espíritu de la lógica hegeliana, implicado en el inocente pero engañoso concepto de superación" y adoptar la lógica del descubrimiento, "de la experiencia efectiva y el surgimiento real que pone fin, a ilusiones del surgimiento ideológico" (Althusser, 2010, p. 67). En una palabra, adoptar la lógica de la irrupción en la ideología misma, tal como vimos en el apartado anterior.

Nos preguntamos, entonces: ¿Cuál es el error del humanismo historicista para Althusser? ¿Cuál es el peligro de la ideología? Según nuestro autor, el problema del humanismo es que no advierte que Marx sólo se convierte en marxista cuando su problemática aparece como original, cuando asume una nueva perspectiva y "se desprende finalmente, se libera de ese fondo ideológico que lo constituye produciendo su inteligibilidad: se autonomiza.”(De Gainza, 2011, p. 93). El humanismo, argumenta Althusser, no ve lo que Marx aporta de nuevo, ni la novedad de sus conceptos, por eso ha buscado sus garantías teóricas en las obras de juventud que contienen los argumentos de una filosofía del hombre, de su alienación y liberación. Su gran equívoco, entonces, es justamente creer que el joven Marx es marxista, y sobre todo, en considerarse a sí mismo marxista y científico cuando no lo es. jIlusa ideología que cree apoyarse en suelo marxista cuando en realidad se ahoga en sus cenizas!, exclama el filósofo.

Althusser afirma un anti-humanismo teórico de Marx y rechaza así las pretensiones teóricas del humanismo socialista. Debemos ser 
sumamente claros en este punto. Para él el humanismo es un concepto ideológico: simplemente señala problemas reales y de suma importancia para el comunismo tanto históricos, como económicos y políticos, los cuales había ocultado el periodo stalinista. . El peligro del humanismo socialista no es que no vea los problemas, sino que los plantea en función de su solución. Allí radica la falsedad epistemológica de la ideología; no es que distorsione lo que ve, sino que presenta falsos problemas y falsas respuestas. Althusser entiende que para plantear y resolver los problemas no basta con señalar, sino que es necesario llamar a las cosas por su nombre:

Al decir que el concepto de humanismo es un concepto ideológico (y no científico), afirmamos que señala un conjunto de realidades existentes pero que, a diferencia de un concepto científico, no nos da los medios de conocerla. [...] Confundir estos dos órdenes sería impedir todo conocimiento, mantener una confusión y arriesgarse a caer en errores (Althusser, 2011a, pp. 205-206).

Allí radica el peligro de esta ideología que oculta los verdaderos problemas bajo una solución falsa. Y sobre todo, allí se encuentra el peligro de que una ideología se arrogue pretensiones teóricas en la confusión entre las funciones de la ciencia y las de la ideología.

\section{La necesidad de la ideología y por qué no puede ni debe ser disipada por la ciencia}

En las secciones anteriores vimos que Althusser resalta una oposición entre la ciencia y la ideología: aquella que concierne a la ruptura entre la ciencia y la ideología teórica en la cual era pensado el objeto de conocimiento de esa ciencia. Comprendimos, además, que aquello que Althusser critica del humanismo como ideología son sus pretensiones teóricas. Estas primeras conclusiones podrían, sin embargo, hacernos caer en un doble error: creer que Althusser condena la ideología y la descarta como mero error o confusión, y entender la ruptura entre la ideología y la ciencia como el pasaje del error a la verdad, de la ignorancia al saber. Muy por el contrario, para Althusser la ideología es necesaria y tiene una función práctica. 
Este hincapié nos indica que existe otra conceptualización sobre la ideología, que aparece ahora como "lo otro" de la ciencia (Catanzaro, 2011, p. 75). Tal como dijo Althusser (2011b) "la ideología manif[iesta] (sic) su existencia y sus efectos no sólo en el terreno de sus relaciones con la ciencia, sino también en uno infinitamente más vasto: el de la sociedad entera” (p. 47). Debemos pues pensar la ideología también en relación a la sociedad, ya que el término ideología invita a una "noción que cuestiona realidades sociales que, aún teniendo que ver con (...) un cierto conocimiento (...) de lo real, desbordan la cuestión del conocimiento, para poner en juego una realidad y una función propiamente sociales" (p. 48). Así, tal como Althusser da a entender en Marxismo y Humanismo, la ideología aparece como "lo otro" de la ciencia, pero ya no como si se tratara de un pasado "menos evolucionado". No se trata sólo del carácter histórico de la oposición sino que ahora, la ciencia aparece como lo otro de la ideología a partir de sus funciones: "podemos decir que la ideología como sistema de representaciones se distingue de la ciencia en que la función práctico social es más importante que la función teórica (o de conocimiento)" (Althusser, 2011a, p. 192). Adentrémonos, entonces, en el “dominio objetivo, social" de esta realidad que es la ideología.

Siguiendo aparentemente las lecciones marxistas, en Marxismo y Humanismo (2011a) Althusser nos presenta una definición, por así decirlo, "marxista clásica" o "convencional" de la ideología como "un sistema (que posee su lógica y su rigor propios) de representaciones (imágenes, mitos, ideas o conceptos), dotados de una existencia y de un papel históricos en el seno de una sociedad dada" (p. 191). Para comprender la función práctica de este "sistema de representaciones", el autor se remite en primera instancia a la teoría marxista de la historia, cuyo "sujeto" son las sociedades humanas. Estas se presentan como formaciones sociales o totalidades orgánicas, cuya unidad está constituida por tres niveles (el económico, el político y el ideológico). En un primer momento, Althusser sostiene que estos sistemas de representaciones son formaciones específicas que se sitúan en la superestructura, con relativa autonomía de la política y el derecho, como dijimos, "clásica". 
Sin embargo, muy poco de la propuesta althusseriana podría ser llamado "convencional". Lo particular de estas representaciones es que "la mayor parte del tiempo, no tienen nada que ver con la conciencia", pues la ideología es "profundamente inconsciente" (p. 193) en el sentido de que las representaciones se imponen a los hombres como "estructuras" sin pasar por su conciencia, como "objetos culturales" que perciben, aceptan y soportan "mediante un proceso que se les escapa". Los hombres "viven" su ideología como su mundo mismo, viven sus acciones, en, a través y por la ideología: "la ideología está presente en todos los actos y gestos de los individuos hasta el punto de que es indiscernible a partir de su 'experiencia vivida"' (p. 49). La ideología, entonces, representa la relación vivida de los individuos con su mundo, y puesto que en la ideología los hombres no expresan su relación con sus condiciones de existencia, sino la manera en que ellos viven esa relación, se trata de una relación compleja, una "relación de relaciones". Esto supone a la vez una relación real -con las condiciones de existencia- que está inevitablemente investida en una relación "imaginaria", en el sentido de "vivida".

En La única tradición materialista (2007), leyendo a Baruch Spinoza, Althusser da cuenta de lo que entiende por imaginación. Para él, la imaginación no es conocimiento, sino "el mundo inmediato tal como nosotros lo percibimos" (p. 135). Por eso, vivimos como bajo el dominio de la imaginación, "no verdaderamente bajo la imaginación sino hasta tal punto penetrado por ella que, propiamente, es indisociable e inseparable de la misma, constituyendo la imaginación su esencia misma, el vínculo interno de todas sus determinaciones" (p. 135). De esta manera, el todo social es siempre opaco para los individuos; esta "opacidad de la estructura social o de lo inmediato", explica por qué la representación que la ideología da de la realidad es una representación que hace alusión a lo real, siendo al mismo tiempo tan sólo una ilusión. Así se comprende que la ideología (como la imaginación) no brinde a los hombres "conocimiento" de su mundo, sino reconocimiento. Este último sólo es posible por el desconocimiento de los mecanismos y de la estructura, que no son inmediatamente visibles, sino opacos, y como veremos, perceptibles en sus efectos. "Los hombres practican su ideología, pero no la conocen”, concluye Althusser. 
¿Cuál es, entonces, la función social de la ideología? En esa relación imaginaria, la ideología refuerza o modifica las relaciones de los hombres con sus condiciones de existencia. Así, contradiciendo a los filósofos comunistas que aseveran que, dado que la ideología es el instrumento de la clase dominante, el advenimiento del comunismo desembocará en el fin de la ideología, Althusser sostiene que todos los hombres, en todas las sociedades, con o sin clases, son transformados por y en la ideología, en virtud de que todos se encuentran sometidos a ella. Por eso, la ideología es indispensable en toda sociedad para formar a todos los hombres, para ponerlos en estado de responder a lo que exigen sus condiciones de existencia. Por lo tanto, la ideología no es un instrumento ni "el cinismo de un mito" o una "bella mentira" fabricada desde el exterior, ya que la clase dominante también se encuentra prisionera y sometida a ella necesariamente, a fin de constituirse en tanto tal. Es decir, ya sea para que acepten la dominación o para que se constituyan en clase dominante en la sociedad de clases, ya para que se organicen en provecho de todos los hombres en una sociedad sin clases, la ideología tiene un papel activo: transformar la actitud y conducta de los hombres, su conciencia, para ponerlos al nivel de sus tareas y sus condiciones de existencia. " $\mathrm{La}$ ideología no es, por lo tanto, una aberración ni una excrecencia de la Historia" sino "que constituye una estructura esencial en la vida histórica de las sociedades", estructura inconsciente que captura a los individuos y define su relación con su mundo (p. 193).

Esa es la función práctica de la ideología, que la hace indispensable a toda sociedad, y que Althusser grafica con las metáforas de la atmósfera, del elemento indispensable, incluso del cemento y lazo que mantiene unido a la sociedad. Al destacar la indispensabilidad y, en consecuencia, la inerradicabilidad de la ideología, Althusser echa por la borda aquellas concepciones iluministas, como diría el argelino francés, que confían en que la ciencia puede reemplazar o disipar a la ideología, que creen que el conocimiento puede disolverla. "Sólo una concepción ideológica del mundo puede imaginar sociedades sin ideologías y admitir la idea utópica de un mundo en el que la ideología (y no una de sus formas históricas) desaparecerá sin dejar huellas para ser reemplazada por la ciencia” (Althusser, 2011a, p. 190). 
La ciencia no reemplaza a la ideología ni puede hacerlo. Según creemos, Althusser comienza a pensar ya desde los primeros años de la década de los sesenta, la heterogeneidad e inconmesurabilidad de los sistemas científicos e ideológicos (Romé, 2011, p. 27). La heterogeneidad está dada por las distintas funciones que cumple cada sistema: función teórica de producción de conocimientos y función práctica de "lazo social", respectivamente (2011c). La contracara de este énfasis en la diferencia de funciones y en la indispensabilidad de la ideología es la asunción de que estas funciones no pueden ser asumidas por la ciencia. Así como Althusser rechaza las pretensiones teóricas de la ideología pero reconoce su función práctica, podemos decir que acepta las pretensiones teóricas de la ciencia, pero rechaza su función práctica (Romé, 2011, p. 27).

Esta es la vehemente lucha de Althusser por llamar a las cosas por su nombre. Ciencia a la ciencia, ideología a la ideología. Sobre todo en un contexto en el que no sólo el humanismo y el historicismo reclamaban pretensiones científicas, sino casi todas aquellas corrientes que se denominaban a sí mismas "ciencias".

\section{La ciencia actual no es la ciencia althusseriana}

Este apartado surge de una "vuelta a Althusser", que implicará remitirnos, particularmente, a un texto un tanto extraño y marginal, muchas veces olvidado y pocas veces rescatado, en relación con los que componen el cuerpo central de su obra, titulado "Filosofía y ciencias humanas", de 1963. En este artículo, publicado en la Reveue de l'enseignement philosophique Althusser responde a una encuesta lanzada por la Association sue les Sciences Humaines sobre la definición de las ciencias humanas y su relación con la filosofía. De las varias intenciones y argumentos que desarrolla en su exposición, nos centraremos en su pregunta sobre el carácter científico de las ciencias actuales: “(...) nos solemos preguntar si todas las disciplinas que se presentan con la etiqueta de «Ciencias Humanas» no sólo son realmente humanas, sino también y ante todo, si son verdaderas ciencias, si el título de ciencia no les sirve, según los casos, de esperanza, de programa, de coartada o impostura" (Althusser, 2008, p. 57). 
Althusser sostiene que las ciencias humanas que se enseñan y aprenden en las universidades y en la academia no son ciencias de verdad, sino que dominadas por la ideología tecnocrática no logran superar el "presente estado de técnicas" en el que se encuentran. Pero si el surgimiento de una ciencia es un tema recurrente en Althusser, su esencia propia es un tema aún más nodal. Prestemos atención a dos cuestiones.

Althusser sugiere que una "verdadera ciencia", es decir, "aquellas disciplinas que merecen verdaderamente el nombre de ciencias" (Althusser, 2011c, pp. 73-75) deben cumplir ciertos requisitos, a saber: tener un objeto propio, una teoría general de su objeto y métodos objetivos de investigación. En sus palabras:

[...] son precisamente esas las condiciones imperativas que definen una ciencia. Sabemos por ello que no es suficiente una realidad sin teoría, ni una teoría sin objeto real, ni un método objetivo ficticio, tan riguroso como se quiera, pero "aplicado" a un objeto presunto para constituir lo que se llama una Ciencia (Althusser, 2008, p. 57).

¿Cuántas de las hoy llamadas "ciencias" cumplen estos requisitos? Siguiendo la lectura althusseriana, nos aventuramos a afirmar que la lista es extremadamente breve: el materialismo histórico, el psicoanálisis - gracias al mérito teórico de Lacan-, y también la lingüística y la fonoaudiología. ¿Qué sucede, por ejemplo, con la psicología o la sociología? El autor las considera disciplinas de vanguardia, espontaneístas, triunfantes consagradas, pero no ciencias. Pretenden ser tales sólo porque emplean métodos que entienden como "científicos", pero que ni siquiera definen en función de un objeto de estudio, porque, argumentará, no lo tienen. Son disciplinas que se someten a intereses y objetivos ajenos a ellas en lugar de construir los propios, y se consagran casi exclusivamente a mejorar y efectivizar técnicas y métodos para servirles mejor. Se hallan en camino hacia la constitución de una técnica eficaz "i[...] como si la precisión de un método hubiera bastado alguna vez para constituir una ciencia!'(Althusser, 2008, p. 59). Efectivamente, Althusser insiste en trazar una línea de 
demarcación entre la ciencia y la técnicas, recalcando la urgencia de criticar las pretensiones teóricas de estas últimas, pues no es posible que cien años después de Marx y cincuenta después de Freud, después de más de un siglo de gestación, aún no se haya podido dar a luz a ciencias de verdad.

Ahora, atendamos a la forma en que el argelino presenta el surgimiento de una ciencia en sus textos más conocidos y visitados. En particular, atendamos a tres imágenes recurrentes y sugestivas. En "Freud y Lacan", elige la imagen del nacimiento de niños no esperados, de hijos de madre soltera, sin padre legal, hijos bastardos a los que la Razón Occidental hace pagar muy caro el hecho de serlo. Estos niños son, nada más y nada menos, que Marx, Nietzsche \& Freud, nacidos, ellos mismos, de ciencias. En segundo lugar, hacia el final del artículo, Althusser toma prestada una nueva imagen con la que el propio Freud definió las repercusiones de su descubrimiento: la revolución copernicana. No se trata de cualquier revolución, sino de aquella que cambió absolutamente la concepción del mundo, la primera herida narcisista al género humano. En tercer lugar, en el prólogo a "Marxismo y Humanismo" y en "La querella del humanismo", la imagen es la del descubrimiento de un nuevo continente: así como Tales \& Galileo agregaron dos continentes al mapa de la ciencia, la matemática y la física, Marx, el nuevo Colón, también abrió un nuevo continente, el de la historia. Nacimiento, revolución, descubrimiento. Tres imágenes que reflejan el carácter disruptivo y explosivo de la emergencia de una ciencia, "irrupciones" en un continuo de ideología del cual emergen y al que interrumpen, "discontinúan"; emergencias "inesperadas" e incluso "perturbadoras", extrañas. Parece, entonces, que el advenimiento de una ciencia no es un fin, sino una "sorpresa" (Althusser, 2010, p. 51).

Sabemos, además, que el nacimiento de una ciencia lejos de ser sencillo, es sumamente arduo y laborioso. Y no sólo eso, una ciencia parece no tener nunca garantizada su existencia, parece no poder nunca anunciarse rotunda y definitivamente como tal. De hecho, el no poder hacerlo aparece incluso como condición para denominarse efectivamente ciencia: "no existe ciencia pura sino a condición de 
purificarla sin descanso, ni ciencia libre dentro de la necesidad de su historia, más que a condición de liberarla sin descanso de la ideología que la ocupa" (p. 140), advierte Althusser en "Sobre la dialéctica materialista" (Althusser, 2011a). En un sentido similar, en el prefacio a Para leer El Capital escribe que una ciencia "no vive sino gracias a una extrema atención puesta en sus puntos de fragilidad teórica (...) lo no-sabido de una ciencia no es aquello que la ideología empirista cree: 'su residuo' [sino] (sic) todo lo que para un oído atento suena a hueco en ella a pesar de su plenitud" (Althusser, 2010, p. 35).

La ciencia no es ni la aplicación de un método, ni una técnica eficaz, ni siquiera aquello que una "buena tradición teórica" pueda garantizar. La ciencia es aquello que pocas veces ha sucedido. "Arduo ciertamente es lo que raramente se encuentra", afirma Spinoza al final de su Ética. Y efectivamente, la ciencia althusseriana se define tanto por la tarea del encuentro, como por lo excepcional de su encuentro. La ciencia althusseriana es "una rareza" (Catanzaro, 2012, p. 76) en tanto experiencia que conlleva un "gran trabajo". Como dice Catanzaro, invirtiendo la famosa tesis sobre la ideología, Althusser podría haber agregado que quien dice que está en la ciencia, está en la ideología (p. 76).

\section{Una teoría general de la ideología y del sujeto}

No quedan dudas acerca la originalidad de la teorización althusseriana sobre la ideología, la ciencia y su relación. Hemos visto que el filósofo critica las pretensiones teóricas de la ideología, pero reconoce su necesidad como cemento de la sociedad, y también que concibe a las ciencias actuales como ideológicas. Sin embargo, es en Ideología y aparatos ideológicos del Estado (1969), un breve texto programático que se hizo rápidamente famoso y que monopolizó los análisis sobre la concepción de ideología para Althusser, en donde nuestro autor se propone postular una teoría explicativa que defina los mecanismos de la ideología, una teoría general de la ideología en el mismo sentido en que Freud propuso una teoría del inconsciente en general. Hablamos de teoría general, como él explica, porque su objeto no son las ideologías particulares, históricas, aquellas que se dicen en plural, sino la 
estructura formal de la ideología, sus elementos y el modo singular en que se combinan y funcionan; sus desplazamientos, invisibilizaciones y transmutaciones. Althusser parte del supuesto de que esta estructura no se observa en la realidad objetiva ni en el núcleo oculto detrás las ideologías particulares, presente en ellas como una verdad escondida. Por el contrario, esta existe en sus efectos. Para Althusser, la ideología puede ser el objeto de una teoría general, puesto que ella "no tiene historia" (Althusser, 2011c, p. 129). Resignificando a ese Marx no marxista de La ideología alemana, entiende que la ideología no tiene historia porque es omni-histórica, en tanto su estructura y funcionamiento están presentes bajo una misma forma en la historia toda y en todas las sociedades; en tanto es eterna, es decir, que no tiene principio ni fin, tan eterna como el inconsciente freudiano, omnipresente e inmutable en la extensión de la historia.

La propuesta althusseriana nace de la crítica a las teorías que en su época se pretenden ciencias de la ideología, que funcionan como crítica de la ideología y conceptualización de lo ideológico. Nos referimos principalmente al humanismo, el cual critica la ideología tomando a los sujetos como dados sin preguntarse por su constitución. Al presuponer la existencia de un "sujeto libre" portador de una conciencia que sustenta ideas en las que cree libremente y en función de las cuales actúa, el humanismo esconde precisamente la pregunta propia de una ciencia de la ideología: aquella por los mecanismos de constitución de los sujetos.

¿Y no existe ya en Marx una teoría de la ideología? No, responde Althusser, pues si bien en La ideología alemana, Marx expone una teoría de la ideología, esta teoría no es propiamente marxista. Muy por el contrario, se asemeja a una concepción empirista del conocimiento que entiende a la ideología como una falsa conciencia de la que hay que desprenderse para aprehender "verdaderamente" la realidad. Entonces, si lo que hay es ideología, si lo que funciona como el modo de conceptualizar lo ideológico es expresión de una ideología, si las críticas de la ideología son ideológicas y si en Marx tampoco está la respuesta, entonces, como dice Althusser, aquello que hay que producir es una teoría marxista científica de la ideología. 
Como vimos, para Althusser, la ideología es necesaria e indispensable para el desarrollo, continuidad y persistencia de una formación social, pues transforma a los hombres y los pone en estado de responder a sus condiciones de existencia. En vocabulario marxista, esto significa que la ideología es esencial para la reproducción de las relaciones de producción. Ahora bien, ¿cómo se asegura esa reproducción? Para responder a esta pregunta, Althusser se ubica en el "punto de vista de la reproducción” (Althusser, 2011c, p. 18) y analiza el concepto de Estado. En polémica con aquellas versiones de la teoría marxista del Estado que reducen al Estado a la distinción entre poder de Estado y aparato represivo del Estado (presentes en el 18 Brumario de Luis Napoleón Bonaparte y Las luchas de clases en Francia), Althusser, a través de una cierta lectura de Gramsci, propone que existen otras realidades distintas al aparato represivo, pero que se manifiestan junto a él: los aparatos ideológicos de Estado. Estas últimas son instituciones precisas y especializadas -como las escuelas, las iglesias, los sindicatos-, cuya característica central es que no funcionan masivamente con violencia (como el aparato represivo), sino "preponderantemente con la ideología" (p. 26). Su función es reproducir las relaciones de producción. Así, podemos afinar nuestra pregunta: ¿cómo aseguran los aparatos ideológicos la reproducción de las relaciones de producción? Para responder esta pregunta en Althusser, necesitamos previamente abordar el estatuto de su teoría general de la ideología.

Antes de adentrarse propiamente en los mecanismos y funciones de la ideología, Althusser postula dos tesis que hacen a su definición. Recordemos aquello que planteamos en el tercer apartado. Allí postulamos que para Althusser, la ideología es "una "representación" de la relación imaginaria entre los individuos con sus condiciones reales de existencia. Tal como vimos en ese momento, lo clave es entender que para Althusser lo imaginario no es ni la representación ni las condiciones de existencia, sino su relación con las condiciones de existencia. Entonces, no se trata de representaciones distorsionadas, ¡culpa de los curas y los déspotas!, como afirman los materialistas franceses del siglo VIII, ni tampoco de una realidad que es falsa en tanto alienada y alienante, como suponen Feuerbach y el joven Marx. De hecho, no se trata de causas de ninguna manera. Entre las 
condiciones del mundo y la representación existe otra realidad: la realidad imaginaria. Por ende, de lo que se trata es de entender por qué es imaginaria, cuál es la naturaleza y efectividad de esta relación como una realidad específica con una consistencia y una materialidad propias. Se trataría de un "materialismo de lo imaginario" (Althusser, 2008, p. 196), lo que conduce a la segunda tesis althusseriana: "la ideología tiene existencia material". Althusser entiende que las ideas de un sujeto humano no brotan de su conciencia para insertarse en prácticas, sino que la existencia de las ideas es material: las "ideas son actos materiales insertos en prácticas materiales, reguladas por rituales materiales definidos, a su vez, por el aparato ideológico material del que proceden las ideas de ese sujeto.” (Althusser, 2011c, p. 50) En una escandalosa frase, que le valió acusaciones de estructuralista acérrimo, Althusser sostiene que "el sujeto actúa en tanto que es actuado' por ese siguiente sistema de "materialidades articuladas" (2011c, p. 138).

Advertimos que el término central y decisivo para entender el mecanismo y efecto de la ideología es uno sólo: el sujeto. Vemos entonces que aquella noción que las teorías ideológicas de la ideología situaban como el principio evidente e incuestionable es, en realidad, el efecto de la ideología. De lo anterior, concluye Althusser, existe una relación fundamental entre la ideología y el sujeto. En la teoría althusseriana, la categoría de sujeto es constitutiva, el sujeto no sólo es el efecto de la ideología, sino su soporte y determinación. Así, la función de la ideología es constituir individuos concretos en sujetos a través de un mecanismo: la interpelación. Esta última es un llamado dirigido a los sujetos, llamado en el que ellos se reconocen, precisamente porque siempre ya han sido sujetos. Así, el proceso ideológico desprende una ficción de temporalización, una ilusión de preexistencia que oculta el complejo mecanismo de la interpelación ideológica que recluta sujetos de entre los individuos. En consecuencia, las dos caras de la función de toda ideología son producir reconocimiento del sujeto a través de "evidencias", imponiéndole el desconocimiento de esa interpelación como interpelación.

Ya hemos visto cuál es el mecanismo y cuál la función de la ideología; Nos resta conocer su estructura. Según Althusser, esta es de centrado 
doblemente especular, es decir, en forma de espejo. Toda ideología está centrada: un Sujeto, con mayúscula, que ocupa el único sitio de centro desde el cual interpela a los individuos en tanto sujetos, llamándolos "por su nombre". Esta estructura garantiza la interpelación de los individuos en tanto sujetos, la sujeción al Sujeto (centro interpelador), el reconocimiento mutuo de los sujetos entre los Sujetos y el sujeto, entre los propios sujetos y del sujeto por sí mismo, y finalmente la garantía de "todo marcha bien". Tenemos así sujetos que caminan por sí mismos, "sujetos sujetados": "el individuo es interpelado en tanto que sujeto (libre) para que se someta libremente a las órdenes del Sujeto, para que acepte (libremente) por tanto su sujeción, (...) para que cumpla por sí mismo los actos y los gestos de su sujeción.” (Althusser, 2011c, p. 62). Hace falta que los individuos desconozcan las formas mismas del reconocimiento que suceden en los aparatos ideológicos del estado para garantizar la reproducción de los medios de producción.

Vemos respondida así nuestra pregunta: ¿cómo garantizan la reproducción de las relaciones de producción los aparatos ideológicos del Estado? A través del mecanismo de interpelación ideológica, de ese discurso ideológico que llama a los sujetos a hacerse cargo de su condición de sujetos, que los hace "vivir" sus ideas como dotadas de independencia y autonomía, y sus prácticas como fruto de su libre albedrío. Así, los hombres se reconocen libres, desconociendo que están sujetados. Y todo marcha bien. "Así sea." (Althusser, 2011c).

\section{Conclusión: "La ciencia es ciencia de la ideología"}

Comenzamos el trabajo afirmando que nuestro hilo conductor sería la frase de Macherey "La ciencia es ciencia de la ideología". Ahora nos encontramos en mejores condiciones para explicarla.

Entendemos que "la ciencia es ciencia de la ideología", en el sentido de que la ciencia nace de la ideología, pues esta constituye la prehistoria de una ciencia, su pasado. Es que la ciencia no trabaja con datos puros, sino que elabora sus propios conceptos a partir de la crítica a los conceptos ideológicos de la práctica teórica ideológica anterior. 
Advertimos, entonces, que la ideología es ideología en un sentido retrospectivo "no pudiendo recibir su nombre de ideología sino a condición de la ciencia de ella nacida y separada de ella" (Althusser, 1967, p. 32). Asimismo, la ciencia siempre lidia con la ideología, porque el trabajo de crítica y de transformación de lo ideológico en científico es constante y porque la ciencia necesita de la ideología para definirse como tal.

"La ciencia es ciencia de la ideología" en una tercera acepción, que implica que es posible sostener una ciencia sobre la ideología, que analice el mecanismo de la interpelación, ese mecanismo que produce como efecto nada más y nada menos que a los sujetos. La ciencia puede construir conceptualmente a un objeto de conocimiento llamado ideología y producir conocimiento sobre ella. Esta fue la empresa que emprendió Althusser, en silencio, durante casi una década, para presentar finalmente su célebremente criticado "Ideología y aparatos del Estado", artículo que fue fruto de un arduo esfuerzo de conocimiento.

Hemos llegado al final de nuestro camino, en el que recorrimos los avatares de la relación entre la ciencia y la ideología en las teorizaciones althusserianas de la década de los sesenta. Un camino en el que fuimos testigos, en última instancia, de que la ciencia es lo otro de la ideología, pero también que la ideología es lo otro de la ciencia, puesto que no existe una relación de continuidad entre ambas en el pensamiento althusseriano. Para el filósofo comunista, la ideología no es una desvirtuación de la realidad de la que la ciencia da un "conocimiento efectivo", ni es un estadio superior de la ideología. Por el contrario, se trata de de dos estructuras diferenciadas no homogéneas, cuya especificidad se encuentra en los mecanismos implicados en cada práctica y en sus efectos. Aquella relación fraternal que Althusser tiene con Freud a través de Lacan imprime consecuencias en su planteo: entender al inconsciente como la deformación de la conciencia es tan ideológico como entender a la ideología como una mera deformación de la ciencia.

"Para conocer a Althusser hay que leerlo", dijo Saúl Karsz en 1970. Este ha sido en última instancia el objetivo de esta investigación. 
Leerlo, como dijimos que él leía a Marx, en forma crítica, al pie de la letra y sin fondo, no sólo para dilucidar sus análisis de la década de los sesenta sobre la relación entre la ciencia y la ideología, sino también para abrazar esa inquietud que nos genera. Abordamos a un Althusser que fue calificado de doctrinario, de marxista acérrimo y de arrogante por desarrollar una filosofía hermética, acusado de postular una teoría de la ideología cerrada y autosuficiente, como un edificio alto y de fuertes paredes, que se alza al lado de la ideología de la ideología. Sin embargo, nos encontramos con un Althusser polémico y belicoso, cuyas teorizaciones no pueden entenderse aisladamente de la crítica a la ideología dominante ni al comunismo de su época, cuyos planteos fueron el resultado de un duro trabajo teórico, de escuchar lo que suena a hueco, de darle voz a los silencios y preguntas a las respuestas.

\section{Referencias}

Althusser, L. (1967). La querella del humanismo. Recuperado de: http:/ files. intervencionalthusser.webnode.cl/200000036-4225d431fe/16175197Althusser-Louis-La-querella-del-humanismo-1967\%5B1\%5D.pdf

Althusser, L. (1985). La única tradición materialista. Youkali, Revista de las artes y el pensamiento (4), 132-154. Recuperado de http://www.youkali. net/youkali4d $\% 20$ Althusser\%20launicatradicionmaterialista.pdf

Althusser, L. (2008). La soledad de Maquiavelo. Madrid: Aka.

Althusser, L (2010). Escritos sobre psicoanálisis. México: Siglo XXI.

Althusser, L. (2011a). La revolución teórica de Marx (segunda edición). México: Siglo XXI.

Althusser, L. (2011b). La filosofía como arma de la revolución (segunda edición). México: Siglo XXI.

Althusser, L. (2011c). Ideología y aparatos ideológicos del Estado/Frend y Lacan. Buenos Aires: Nueva Visión.

Althusser, L. (2012). Para leer El Capital. México: Siglo XXI.

Burdman, J. (2011). Distorsión, transparencia y universalidad en la teoría de la ideología. En S. Caletti, N. Romé \& M. Sosa (Comps.). Lecturas de Althusser: Proyecciones de un campo problemático, (pp. 79-96). Buenos Aires: Imago Mundi. 
Catanzaro, G. (2012). Perseverante Impropiedad: Consideraciones sobre la relación entre política y conocimiento. En Memorias de las II Jornadas Espectros de Althusser: diálogos y debates en torno a un campo problemático. Buenos Aires: Universidad de Buenos Aires, Facultad de Ciencias Sociales.

De Gainza, M. (2011). La actualidad de la lectura sintomática. En S. Caletti \& N. Romé (Comps.). La interverción de Althusser, hoy: Revisiones y debates, primera edición, (pp. 241-257). Buenos Aires: Prometeo.

De Gainza, M. (2012). La política en la filosofía: la potencia de la distinción. En Memorias de las II Jornadas Espectros de Althusser: diálogos y debates en torno a un campo problemático. Buenos Aires: Universidad de Buenos Aires.

Gassmann, C. (2011). Sobre lo que dijo ser y lo que fue la lectura sintomática de Althusser. En S. Caletti, N. Romé \& M. Sosa (Comps.). Lecturas de Althusser: Proyecciones de un campo problemático. Buenos Aires: Imago Mundi.

Gassmann, C. (2013). La ruptura epistemológica según Bachelard, Althusser y Badiou. Estudios de Epistemología X Revista digital del instituto de epistemologia, (10), 35-52. Recuperado de: http://www.aacademica.com/ pedro.karczmarczyk/12.pdf

Kolakowski, L. (1983). Las principales corrientes del marxismo III. En La crisis. Madrid: Alianza.

Martín, F. (2011). Sujeto e ideología n Althusser y Adorno. En S. Caletti, N. Romé \& M. Sosa (Comps.), Lecturas de Althusser: Proyecciones de un campo problemático, (pp.151-166). Buenos Aires: Imago Mundi.

Romé, N. (2009). Avatares de una relación. Algunas notas sobre el vínculo entre la ciencia y la ideología en la obra de Louis Althusser. V Jornada de Jóvenes Investigadores IIGG, Buenos Aires, Argentina.

Sosa, M. (2011). Presentación a Lecturas de Althusser: Proyecciones de un campo problemático. En S. Caletti, N. Romé \& M. Sosa. Lecturas de Althusser: Proyecciones de un campo problemático, (pp.7-17), Buenos Aires: Imago Mundi.

Terriles, R. (2011). Sujeto y lazo social en la teoría de la ideología de Loius Althusser. En S. Caletti, N. Romé \& M. Sosa (Comps.). Lecturas de Althusser: Proyecciones de un campo problemático, (pp. 39-56). Buenos AiresCABA: Imago Mundi. 